Association for Information Systems

AIS Electronic Library (AISeL)

AISWN International Research Workshop on

Women, IS and Grand Challenges 2020

AIS Womens Network College

$12-13-2020$

\title{
Gender Bias in Information Systems Research: A Literature Review
}

Silvia Masiero

University of Oslo, silvma@ifi.uio.no

Aleksi Aaltonen

Temple University, aleksi@temple.edu

Follow this and additional works at: https://aisel.aisnet.org/aiswn2020

\section{Recommended Citation}

Masiero, Silvia and Aaltonen, Aleksi, "Gender Bias in Information Systems Research: A Literature Review" (2020). AISWN International Research Workshop on Women, IS and Grand Challenges 2020. 2.

https://aisel.aisnet.org/aiswn2020/2

This material is brought to you by the AIS Womens Network College at AIS Electronic Library (AISeL). It has been accepted for inclusion in AISWN International Research Workshop on Women, IS and Grand Challenges 2020 by an authorized administrator of AIS Electronic Library (AISeL). For more information, please contact elibrary@aisnet.org. 


\title{
Gender Bias in Information Systems Research: A Literature Review
}

\author{
Completed Research Paper
}

\author{
Silvia Masiero \\ Department of Informatics \\ University of Oslo \\ Ole-Johan Dahls Hus, Gaustadalleèn 23B \\ N-0373 Norway \\ silvima@ifi.uio.no
}

\author{
Aleksi Aaltonen \\ Fox School of Business \\ Temple University \\ 1801 Liacouras Walk \\ Philadelphia, PA 19122 USA \\ aleksi@temple.edu
}

\begin{abstract}
Gender bias is a systemic, unfair difference in the way men and women are treated in a particular domain. We conduct a thematic review of 82 papers out of 7,26o total papers found in the IS Basket of 8 journals that centre on themes related to gender, identifying extant domains of contribution and qualifying gaps in gender bias research. The papers fall into three broad categories that i) incorporate gender as a variable in empirical research, ii) study gender imbalances in the IT industry, or iii) discuss gender bias in the academic IS profession. Based on the review, we delineate an agenda for further work to investigate the role of gender in the IS academic space.
\end{abstract}

Keywords: Academic IS, Gender bias, Gender imbalance, Literature review

\section{Introduction}

Gender bias is a systemic, unfair difference in the way men and women are treated in a particular domain. Gender biases are a well-known phenomenon in the psychological literature (Ceci \& Williams, 2011; AlGazali, 2013; Shen, 2013), and the recognition of potential gender biases has inspired a large body of research on employment opportunities, expectations and career progression across industries (Annabi \& Lebovitz, 2018) as well as in different academic disciplines (Handley et al., 2015; Hengel \& Moon, 2018; James et al., 2019). In the context of the academic profession, gender biases have been broadly documented in hiring decisions (Moss-Racusin et al., 2012), publication quality perceptions (Knobloch-Westerwick et al., 2013), research publications (Hengel \& Moon, 2018), peer review (Helmer et al., 2017), citations patterns (Lariviere et al. 2013), and in the likelihood of earning tenure (Jaschik, 2014).

The IT industry and, mimicking its subject matter, academic IS research are historically male-dominated professional domains. There is a body of IS literature on gender imbalances in the IT industry and its perception by female and male employees (cf. Trauth, 2002; Trauth \& Howcroft, 2006; Robert et al., 2018). A substantial part of this literature pertains specifically to interventions to retain women in IT companies, indicating an active interest among IS scholars in inspiring, informing and evaluating practical actions to reduce the gender gap in the industry (von Hellens et al., 2012; Panteli, 2012; Annabi \& Lebovitz, 2018). At the same time, research on gender bias in IS academia in terms of publishing, citation patterns, perceived quality of work, peer review, hiring and tenure decisions is much more limited. This is worrying especially when balanced against indications that gender shapes the careers of women and men in IS academia (Wilson, 2004; Gupta et al., 2019; Winter \& Saunders, 2019).

This paper is a part of an effort to assess gender bias in IS through bibliometric analysis, which emerged from the authors' personal experiences and observations of our field as well as of our knowledge of extant accounts of gender biases in IS (Gupta et al., 2019, Winter \& Saunders, 2019). These prompted us to conduct 
a literature review on gender in the IS field, with a focus on gender bias and the ways in which it has been incorporated into core IS research. We conduct a thematic review of 82 papers out of 7,260 total papers found in the IS Basket of 8 journals that centre on themes related to gender, identifying extant domains of contribution and qualifying gaps in gender bias research. The papers fall into three broad categories that i) incorporate gender as a variable in empirical research, ii) study gender imbalances in the IT industry, or iii) discuss gender bias in the academic IS profession. Based on the review, we delineate an agenda for further work to investigate the role of gender in the IS academic space.

This paper is structured as follows. We first introduce the concept of gender bias, marking its difference with gender imbalance and discussing how it has been studied across academic disciplines. We then move to our literature review of gender in the Basket of 8 journals, providing a comprehensive overview of what is known about gender bias in IS. Finally, we outline a research agenda to help IS scholars to engage gender bias more effectively, combining both aspects of theorisation and practical relevance in their work.

\section{Gender Bias}

The Cambridge dictionary defines gender bias as an "unfair difference in the way men and women are treated". A bias is a tendency or inclination that subverts objectivity and distorts accurate perceptions of scientific evidence by the general public (Carnes, 2012; De Melo-Martin \& Intermann, 2012, cited in Handley et al., 2015). Psychological literature has engaged gender bias in behavioural terms, identifying it as a tendency that results in behaviours that penalise women, or favour men, in specific contexts. For example, Handley et al. (2015) design three experiments which reveal that men and women perceive experimental evidence on gender bias differently. Results across the experiments show that men evaluate gender-bias research less favourably than women, a difference that was especially prominent among STEM academics. More generally, the literature on gender focuses on the workplace (Ceci \& Simon, 2011) as a site where biases grounded on gender perceptions have tangible consequences for individuals.

Gender biases are often subtle and thus difficult to prove to be deliberate or even exist a particular situation. At the same time, they result in systemic behaviours that penalise women - and favour men - in professional, academic or social settings on average. For example, a study by Budden et al. (2008, cited in Ceci \& Simon 2011) analysed journal acceptance rates for papers submitted to Behavioral Ecology by female authors, after the journal began blind peer review. The acceptances for female first-authored manuscripts increased by $7.9 \%$ in the four years after the onset of blind review suggesting that when reviewers were aware of authors' gender, they were less likely to accept women's manuscripts. Subtle gender bias are often stochastic in the sense that it is difficult to observe discrimination in any individual event with certainty, yet the overall pattern of discrimination is clear. This has inspired literature centred on industry, sports and social activities, and academia to focus on "subtle gender biases" (Handley et al., 2015). Accordingly, we focus on such subtle biases as distinct from outright gender discrimination in the academic IS discipline in our research for two reasons. First, "ever-growing empirical evidence documents a gender bias against women - and favoring men - in science, technology, engineering, and mathematics (STEM) fields" (Handley et al., 2015). Table 1 illustrates the breadth of biases found in these fields, which raises an obvious question on whether similar patterns exist in our discipline.

\begin{tabular}{|l|l|l|}
\hline Activity & Reference & Key findings \\
\hline $\begin{array}{l}\text { Hiring } \\
\text { decisions }\end{array}$ & Reuben et al. (2014) & $\begin{array}{l}\text { The authors design an experiment to isolate discrimination's potential } \\
\text { effect. They find that, without provision of information about candidates } \\
\text { other than their appearance, men are twice more likely to be hired for a } \\
\text { mathematical task than women. }\end{array}$ \\
\hline $\begin{array}{l}\text { Publication } \\
\text { quality } \\
\text { perceptions }\end{array}$ & $\begin{array}{l}\text { Knobloch-Westerwick } \\
\text { et al. (2013) }\end{array}$ & $\begin{array}{l}\text { The authors design an experiment in which participants rate conference } \\
\text { abstracts ostensibly authored by females or males, with author } \\
\text { associations rotated. Abstracts fell into research areas perceived as } \\
\text { gender-typed or gender-neutral. Findings reveal that publications from } \\
\text { male authors were associated with greater scientific quality, in particular } \\
\text { if the topic was male-typed. }\end{array}$ \\
\hline
\end{tabular}




\begin{tabular}{|l|l|l|}
\hline Peer review & Helmer et al. (2017) & $\begin{array}{l}\text { The authors use public information about the identities of 9,ooo editors } \\
\text { and 43,00o reviewers from Frontiers journals. They show that women are } \\
\text { underrepresented in the peer-review process, that editors of both genders } \\
\text { operate with substantial same-gender preference (homophily), and that } \\
\text { the mechanisms of this homophily are gender-dependent. }\end{array}$ \\
$\begin{array}{l}\text { Research } \\
\text { citations }\end{array}$ & Lariviere et al. (2013) & $\begin{array}{l}\text { A study of research output shows that in the most productive countries, } \\
\text { all articles with women in dominant author positions receive fewer } \\
\text { citations than those with men in the same positions. }\end{array}$ \\
\hline $\begin{array}{l}\text { Tenure } \\
\text { decisions }\end{array}$ & Jaschik et al. (2014) & $\begin{array}{l}\text { The study raises questions about why women are less likely than men to } \\
\text { earn tenure at research universities. The starting point of the study are } \\
\text { statistics revealing gender imbalances in tenure decisions in US } \\
\text { universities. }\end{array}$ \\
\hline
\end{tabular}

Table 1. Gender biases in STEM fields

Second, there is paucity of studies into the topics listed in Table 1 in the IS field (Gupta et al., 2019; Winter \& Saunders, 2019), implying the need to start from how such studies are conducted in neighboring fields. For instance, Hengel and Moon (2018) show that articles published in top economics journals authored by men are cited less than those published by women. They also find that men's citations rise when they coauthor with women, while women's citations fall when they co-author with men. The authors state that "under strong - but we believe reasonable - assumptions, our findings imply top economics journals hold female-authored papers to higher standards and, as a result, do not publish the highest quality research". Biases of this type end up affecting the quality of the research published in academic journals, hence hurting the discipline, rather than only those who are discriminated against.

Finally, overt discrimination falls, at least to some extent, to the remit of academic employers. These have often taken measures to alleviate some of the worst forms of discrimination at the academic workplace. By contrast, addressing subtle biases can only be done by the IS community itself. To lay grounds for such a project and, importantly, do justice to the extant literature on gender in IS, we review how gender and the biases associated to it have been studied in our field.

\section{Gender Bias in IS: A Literature Review}

Having mapped how gender bias is studied in other fields, we now turn to what the IS literature has said about gender bias. To do so, we start from a broad mapping of how gender features in top journals of our field. Using relevant keywords (gender, gender bias, gender discrimination, gender inequality, male bias, stereotyping, sexism) we searched all Basket of 8 journals for all years, resulting in 312 papers that include at least one of the specified keywords in the title, abstract or keywords. Our search keywords were discussed with expert researchers of gender bias in other fields (psychology, STEM), which helped to refine the set of keywords for the literature search in IS journals. The two authors then independently coded the papers as "relevant" or "not relevant" to any form of research on gender, arriving at 86 papers classed as relevant for our research. The criterion in deciding on relevant vs. non-relevant papers consisted in identifying all papers involving gender in the formulation of the research, even if the topic was mentioned just tangentially. Discrepancies in assigned codes between the two authors were resolved by discussing each item individually.

We identify three clusters of gender-related research in IS. In the first cluster (Type 1), gender is a variable such as one of many control variables in the context of research effort that is set out to study some topic within the IS field. The second cluster (Type 2) investigates gender imbalances in the IT industry and interventions to address it. Finally, the third, much smaller cluster of only 8 papers (Type 3) focuses on forms of gender bias in the academic field of IS. The number of papers for each type is summarized in Table 2. 


\begin{tabular}{|l|l|l|l|}
\hline Type & Label & $\mathrm{N}\left(86^{*}\right)$ & Focus \\
\hline $\mathbf{1}$ & Gender as explanatory variable & 19 & Gender effects; not gender bias \\
\hline $\mathbf{2}$ & Gender imbalance in IS field & 23 & $\begin{array}{l}\text { Causes, consequences, and interventions } \\
\text { regarding gender imbalance in the IS workplace }\end{array}$ \\
\hline 3 & Gender bias in IS academia & 8 & $\begin{array}{l}\text { Critical perspective; studying gender in IS } \\
\text { workplace }\end{array}$ \\
\hline
\end{tabular}

${ }^{*}$ Gender as control variable removed from Type $2(n=36)$

Table 2. Number of papers for each type

\section{Type 1: Gender as Explanatory Variable in IS Research}

Papers identified as Type 1 in our research use gender as a variable in the conduct of studies that do not pertain to gender bias, women underrepresentation or gender imbalances of any form. These papers use gender as a variable in the investigation of different topics: these range from technology acceptance and use, attitudes towards technology, and similar extensions or applications of existing theoretical models (TAM, UTAUT) to research on less explored areas, such as attitudes towards data protection regulation (Foth, 2016) or knowledge sharing among bloggers (Chai et al., 2011). In reviewing this body of literature, we found it useful to draw a distinction between papers that use gender as the main variable (or, one of the main variables) in their investigation, and papers which only use gender as a control variable in a study that tests for something else. We identify 19 papers with gender as the main variable, which we termed OT1, and 36 papers with gender as a control variable, termed OT2.

An important point to be raised here is that many of the papers excluded from our review, termed as "not relevant" in our dataset, either fall in the OT2 type or use gender as a descriptor of a data sample, not drawing gender-related inferences in the findings. The boundary between "not relevant" (paper that does not pertain to gender) and OT2 (paper that only uses gender as a control variable) was hence malleable in the first stages, and only our definition of OT2 as "papers that use gender as control variable", formulated during the research process, has led to a clear distinction between the two.

The common denominator of Type 1 papers is that whatever their research focus, it is not gender bias (or, more extensively, gender imbalances or women underrepresentation) that they deal with. In the case of OT2, gender is just a control variable in studies of disparate topics, such as affective relations to technology (Agogo \& Hess, 2018), online trust (Hoffman et al., 2014), adoption of mobile data services (Kim \& Han, 2019), or classifications of IT users (Berente et al., 2011). These papers are, as a result, only marginally relevant to our research: they are indeed studies that take gender into consideration, but such consideration only takes the form of control and does not directly engage the effects of gender as a main variable in the formulation of questions.

In the case of OT1, instead, gender is set as either the only variable, or one of the main variables, in the formulation of the research questions and elaboration of findings. These papers usually display clear gender effects: Krasnova et al. (2017) find that people of different genders use social networking sites for different reasons. Foth (2016) finds that people of different genders have different attitudes to data protection regulation. Zahedi et al. (2006) find that the same websites, with the same characteristics, have different meanings for men and women. Papers of the OT1 type are relevant to our research because they are studies of gender: they start from the hypothesis that gender will influence some technology-related dependent variable. In some cases, such as Shen (2010), these papers even recognise extant bodies of literature on gender differences in IT adoption and usage. The high number (55) of Type 1 papers in our dataset leads us to the observation that in IS top journals, gender has been treated primarily as a variable (main or control) in the study of technology and attitudes towards IT.

\section{Type 2: Gender Bias in the IT Industry}

The second, substantial cluster are papers that engage with the IT industry, starting from statistics about underrepresentation of women in the IT profession. The focus of these studies is, with only two exceptions stated below, on the Western IT industry, with studies concentrated in North America and, in lesser quantity, Europe. These papers engage with gender imbalances and, more rarely, with the biases leading to 
them. Several papers revolve on interventions to mitigate women underrepresentation in the IT industry, hence defining a cluster of papers that directly matters to our gender bias research.

Of Type 2 papers, many are empirical studies that note the underrepresentation of women in IT. The way they treat such underrepresentation, however, differs across studies. We follow Gorbacheva et al. (2019) in identifying three clusters of IS research on women in the IT industry, whose common denominator is the focus on women's underrepresentation:

1) Research on causes of gender imbalance in the IT profession. A first cluster of research seeks to identify the factors behind gender imbalances, keeping in mind the point - made in Section 2 - that while gender bias is an unfair difference in the way men and women are treated, gender imbalance is a (possible) byproduct of gender bias, and consists in the statistical underrepresentation of women in a given industry or field, or in a part of it (boards of directors, editorial councils, and so on). Papers belonging to this cluster interrogate the reasons behind gender imbalance: Trauth \& Howcroft (2006) make a critical study of women in the US IT industry, inquiring their conditions of work and the injustices that they perceive. Quesenberry et al. (2012) make a mixed-methods investigation of career anchors of women in the US IT workforce, aimed at generating within-gender theory on women's motivations the IT profession. While these studies used primarily essentialist and social constructionist perspectives to account for causes of the gender gap in IT, a review by Ridley \& Young (2012) identifies these approaches in juxtaposition to a third one, Trauth's (2002) theory of individual differences within gender in IT, which is increasingly used over time to account for the gender pay gap and is today recognised as one of the core approaches in researching the topic.

2) Research on consequences of gender imbalance in the IT profession. A second set of papers looks at the consequences of gender imbalance, observing women's reactions to being underrepresented in the IT industry and the decisions made in response to it (e.g. staying within the industry, or leaving). Kirton \& Robertson (2018) make a qualitative study that explores women's experiences in a UK-based IT company, showing how components of organisational regimes contribute to maintaining inequality in the IT workplace. Armstrong et al. (2018) use Ahuja's (2002) model to understand the challenges that women face in the IT profession. Joseph et al. (2015) analyse competing risks of male and female IT professionals' job mobility and relative pay gap, which can be seen as both a cause and a consequence of gender imbalance in the IT profession (Trauth, 2002). Reflection on themes such as the pay gap may make the line between this cluster and the previous one blurred, as some papers investigate topics gender pay gaps, perceived injustice - that are causes for women's reluctance to enter the industry, but can as well be seen as consequences of the power asymmetries fostered by limited representation.

3) Research on interventions to address gender imbalance in the IT profession. A third stream of research, whose importance has been widely recognised in recent IS conferences, focuses specifically on interventions to address gender imbalances in the IT industry. A special issue of ISJ (von Hellens et al., 2012) focuses specifically on such interventions: within it, Panteli (2012) evaluates an intervention programme for women returning to the industry following a career break. Craig (2015) develops an evaluation framework for computing interventions aimed at improving gender balance in the IT profession. Annabi \& Lebovitz (2018) develop a framework to understand interventions to retain women in IT companies, based on case studies of nine organisations. While most of these works use extant frameworks to develop evaluations of interventions, calls are made to convert such evaluations into action research to improve such interventions (von Hellens et al., 2012).

Two Type 2 studies fall outside this three-pronged classification. These are studies that do not focus on the Western IT industry, but on developing country contexts, respectively impact sourcing in Pakistan (Malik \& Nicholson, 2019) and women intermediaries of technology in India and China (Oreglia \& Srinivasan, 2016). The study by Malik and Nicholson conceptualises gender within the formation of a family-centred institutional logic that limits women's ability to join impact sourcing. Differently, the study by Oreglia and Srinivasan conceptualises the role of gender in relation to technology intermediation in two developing country contexts. While these two studies do not relate to the IT industry in its Western conception, they clearly conceptualise the position of women and detail forms of gender oppression that they are subjected to.

To sum up, IS research engages with gender imbalance in one of its main research objects, that is the IT industry and its professionals. Within this domain, imbalances are researched in terms of their causes, 
consequences and interventions to address them, and a focus on gender bias - as unfair differences in how men and women are treated - is recognised in a subset of the publications. This leads us to observe that IS is a field in which gender bias is indeed researched, but - unlike psychology, economics, and the STEM disciplines discussed above - such research by-and-large focuses on the industry that our field studies, rather than the academic field itself.

\section{Type 3: Gender Bias in IS Academia}

Across our whole dataset, we find a total of eight papers that take issue with gender imbalance - in three cases, explicitly with gender bias - in IS academia. The number - very small considering the total number of articles published in Basket of 8 journals - should be seen with two contextual caveats: first, only a limited number of papers in Basket of 8 journals consists in reflections on the field, and in fact such metareflections are normally found in editorials and introductions to special issues (five of the eight papers in this cluster are of this type). Secondly, our review of Type 2 papers has revealed that the IS field studies gender imbalances mainly in terms of a core research object, that is the IT industry. While in this light it might be less surprising to see fewer papers on gender imbalances in IS academia, the paucity of such studies stands out in comparison to studies of disciplines such as psychology, economics, or the STEM fields.

The papers that do engage gender bias in academic IS, however, are clear in their indications on (a) the presence of gender biases in IS academia, and (b) the importance of studying this phenomenon in the context of the IS academic community. Out of the eight Type 3 papers, three are journal editorials, two are studies of - respectively - academic publications in IS and editorial advisory boards of IS journals, and three are pieces of critical research that openly bring to light issues of gender bias in the IS academic community. These papers canbe classified as belonging to three respective clusters of journal analysis, research practices, and forms of gender bias in IS academia. Core contents are summarised in the points below.

1) Avison et al. (2008) and Avison \& Myers (2012) are papers that reflect on, respectively, the first 17 years and the first 25 years in operation of the Information Systems Journal (ISJ). The two papers feature a passage - phrased almost identically in the two manuscripts - that states:

"A gender imbalance also concerns us. The fact that the percentage of female authors has increased from $14.4 \%$ (volumes 1-6) to $19.8 \%$ (volumes 13-17) is a move in the right direction but it still indicates a structural problem; probably a reflection of a wider issue which is the gender imbalance in universities, including in our domain." (Avison et al., 2008: 8)

"A gender imbalance also concerns us. The fact that the percentage of female authors has increased from $14.4 \%$ (volumes 1-6) to $19.8 \%$ (volumes $13-17$ ) and now further to $28 \%$ are moves in the right direction but still indicates a structural problem; probably a reflection of a wider issue which is the gender imbalance in universities, including in our domain. However, we are hopeful that our special issue on 'Women and IT' that will be published later this year (edited by Liisa von Hellens, Julie Fisher and Eileen Trauth), will at least partly address this issue." (Avison et al., 2012: 185).

The Special Issue pointed out by the Editors (von Hellens et al., 2012), however, is part of the Type 2 cluster we reviewed above, specifically of the subsection of the cluster that deals with interventions to tackle gender imbalance in the IT industry. Avison and Fitzgerald (2012) hence conflate research on gender imbalances in IS academia with research on gender imbalances in the IT industry: unfortunately, it is hard to see how a contribution to Type 2 (on which a substantial IS literature exists) may help address the gap in Type 3 .

2) Winter and Saunders (2019) discuss the relation between personal and policy dimensions, using the example of gender equality to show the choices an IS academic can make to reinforce or change existing policies. The paper is not in itself centred in issues of gender in IS academia, but it uses gender inequalities - framed as traits in the bias lexicon as unjust differences - as a means to reflect on the consequences personal choices have on policy, echoing the stream of action research leveraged in Type 2 papers. 
3) Burgess et al. (2017) and Gallivan et al. (2007) are, respectively, studies of editorial boards in IS journals and publications in IS journals. On the one hand, none of the two studies is particularly focused on gender, as the former looks at diversity (or lack thereof) in editorial advisory boards under multiple dimensions and the latter only includes gender in the set of variables along which commonly accepted rankings of IS journals are not diverse enough. Despite the presence of good clues in both papers, none of them develops the gender dimension of the problem, which is left for further research to deal with.

4) Finally, papers authored by Adam (2002), Wilson et al. (2004), and Gupta et al. (2019) give clear indications on studying gender bias in the IS academic field, with a focus that varies from IS research to membership of the IS academic community. Because of the importance of these papers to our study, we offer a summary of the key points of each:

- Adam (2002) makes the core hypothesis that if technical skill and masculinity are fundamentally related, then women working in IT challenge masculine skills by gaining them, hence must develop strategies to cope with the challenge that they feel is being made to their own gender identities. The paper presents critical research that seeks to expose asymmetric power relations in the organisation and to let silenced voices be heard. It finds that women adopt two coping strategies: to distance themselves from IT work or to distance themselves from their identities as women.

- Wilson (2004) builds a conceptual framework for studying gender in IS research. The paper takes a critical and feminist approach to the organisational context of IS development and use. The proposed conceptual framework for studying gender and IS combines insights from (1) gender and computing - inequalities of development and use of IS; (2) gender and society - existence of gendered spheres; (3) studies of gender and organisations concerning the social division of labour; and (4) gender and technology - the masculinity of technology culture.

- Gupta et al. (2019) note how gender shapes the careers of women and men in IS in relation to their employing institutions and to the Association for Information Systems (AIS). The paper makes a survey of 279 AIS members, which offers insights into whether women and men feel equitably treated in terms of support, job satisfaction, opportunities for career advancement, quality of mentoring, and sexual harassment in their AIS interactions and at their employing universities.

To sum up, papers focusing on gender bias in IS academia give clear indications of the presence of a gender bias in the field, its consequences on women members of IS academia, and the importance of studying its extension, traits and outlook in terms of variables (e.g. hiring decisions, publications, citations, composition of editorial boards, tenure decisions) such as those examined for other fields. It is worth noting that the two articles that directly engage gender bias in IS academia are very recent and published in the same journal, the Journal of the Association of Information Systems. Based on these insights, we leverage our literature review to propose an agenda for such research.

\section{Final Remarks}

Research on gender bias, defined as unfair difference in how men and women are treated, is widely diffused across academic disciplines. Against this backdrop, lack of awareness of a body of research investigating gender bias in the field of IS triggered our interest in finding out how IS treated the topic of gender, and how - if at all - it investigated biases in this respect. Such an interest motivated our decision to undertake the literature review presented here, which has mapped publications on gender and gender biases across Basket of Eight journals. Such a review inspires some suggestions for a future research agenda.

First, the number of works engaging gender bias in IS academia is very limited. However, our review has illuminated an extensive body of research on gender biases in the IT industry, very well rooted in IS top journals and constituting a decades-long tradition of research in the field. A recent study of editorial board diversity on Basket of 8 journals (Beath et al., forthcoming) illustrates that all journals fall below what might be reasonably expected regarding gender, as well as regional or ethnic diversity. This inspires the suggestion that theories used to illuminate such a topic, such as Trauth's (2002) individual differences theory, can provide the intellectual tools to research gender bias in the IS academic domain, observing - for example the causal roots of gender imbalances in publications such as those reported by Avison et al. (2008) and Avison and Fitzgerald (2012). While not theorised through such conceptual tools, such imbalances call for 
research that traces their causes, in the light of developing interventions such as those explored by researchers of the IT industry (Type 2 papers).

Second, a substantial part of evidence of gender bias in IS research can be described as anecdotal (that is, till systematic explanatory studies like those suggested here are undertaken). But the systematicity of such evidence cannot be ignored, and can be seen as a recurring theme in IS women symposia such as meetings of the AIS Women's Network. Personal experiences such as those narrated by Gupta et al. (2019) constitute a common theme within such symposia, and can be said to be an integral part of an IS academic woman's route into the field. By way of example, the first author on this paper received an evaluation of 3/7 on "quality of presenters" in a proposed panel session in one of the IS conferences, in a non-blind review process for a panel proposal authored by four women experts in the field. Anectodal as it may be, evidence of subtle gender bias is present in women's narration of their experience of being in the field, and even that alone constitutes a strong reason to engage research efforts aimed at explaining such biases.

Third, research on gender bias in other disciplines can be an important guiding light to begin such an effort on journal analysis, research practices and gender bias in IS academia. Studies of gender bias covered in our review are mostly quantitative papers that map biases in relevant aspects of academia such as publications, citations, peer review, hiring and tenure decisions. While flagging the need for studies of this type in the IS field, we raise, at the same time, the need for studies that explore the qualitative aspects of bias, such as the lived experience of it - discussed in the paper by Gupta et al. (2019) - and the dynamics leading to crystallisation of imbalances, such as those explored, for the IT industry, in the critical research study by Trauth and Howcroft (2006). Our suggestion calls, therefore, for a combination of quantitative assessment of gender bias and qualitative analyses of it, coupling statistical mappings of the phenomenon with lived experiences of its functioning.

In conclusion, this paper joins a conversation on gender bias in IS academia which, while sustained by a limited number of papers, finds strong support in literature on other fields, IS studies of the IT industry, and the lived experiences of women in IS. We do hope that our literature review triggers action on the points proposed in this research agenda, for a fair and detailed exploration of gender-related patterns in our field.

\section{References}

Adam, A. (2002). Exploring the gender question in critical information systems. Journal of Information Technology, 17(2), 59-67.

Agogo, D., \& Hess, T. J. (2018). "How does tech make you feel?" a review and examination of negative affective responses to technology use. European Journal of Information Systems, 27(5), 570-599.

Ahuja, M. K. (2002). Women in the information technology profession: A literature review, synthesis and research agenda. European Journal of Information Systems, 11(1), pp. 20-34.

Al-Gazali, L. (2013). Remove social barriers for women scientists. Nature 495: 35-36.

Annabi, H., \& Lebovitz, S. (2018). Improving the retention of women in the IT workforce: An investigation of gender diversity interventions in the USA. Information Systems Journal, 28(6), pp. 1049-1081.

Armstrong, D. J., Riemenschneider, C. K., \& Giddens, L. G. (2018). The advancement and persistence of women in the information technology profession: An extension of Ahuja's gendered theory of IT career stages. Information Systems Journal, 28(6), pp. 1082-1124.

Avison, D., \& Fitzgerald, G. (2012). Reflections and opinions on 25 years with the ISJ. Information Systems Journal, 22(3), pp. 179-193.

Avison, D. E., Dwivedi, Y. K., Fitzgerald, G., \& Powell, P. (2008). The beginnings of a new era: time to reflect on 17 years of the ISJ. Information Systems Journal, 18(1), pp. 5-21.

Beath, C., Chan., Y, Davison, R., Dennis, A., Recker, I. (forthcoming). Editorial Board Diversity at the Basket of Eight Journals: A Report to the College of Senior Scholars. Communications of the Association for Information Systems, forthcoming.

Berente, N., Gal, U., \& Hansen, S. (2011). Ethical implications of social stratification in information systems research. Information Systems Journal, 21(4), pp. 357-382. 
Budden, A. E., Tregenza, T., Aarssen, L. W., Koricheva, J., Leimu, R., \& Lortie, C. J. (2008). Double-blind review favours increased representation of female authors. Trends in Ecology \& Evolution, 23(1), pp. 4-6.

Burgess, T. F., Grimshaw, P., \& Shaw, N. E. (2017). Research Commentary-Diversity of the information systems research field: A journal governance perspective. Information Systems Research, 28(1), pp. 5-21.

Carnes, M., Devine, P. G., Isaac, C., Manwell, L. B., Ford, C. E., Byars-Winston, A., ... \& Sheridan, J. (2012). Promoting institutional change through bias literacy. Journal of Diversity in Higher Education, 5(2), 63.

Ceci, S. J., \& Williams, W. M. (2011). Understanding current causes of women's underrepresentation in science. Proceedings of the National Academy of Sciences, 108(8), pp. 3157-3162.

Chai, S., Das, S., \& Rao, H. R. (2011). Factors affecting bloggers' knowledge sharing: An investigation across gender. Journal of Management Information Systems, 28(3), pp. 309-342.

Craig, A. (2015). Theorising about gender and computing interventions through an evaluation framework. Information Systems Journal, 26(6), pp. 585-611.

De Melo-Martín, I., \& Intemann, K. (2012). Interpreting evidence: why values can matter as much as science. Perspectives in Biology and Medicine, 55(1), 59.

Foth, M. (2016). Factors influencing the intention to comply with data protection regulations in hospitals: based on gender differences in behaviour and deterrence. European Journal of Information Systems, 25(2), pp. 91-109.

Gallivan, M. J., \& Benbunan-Fich, R. (2007). Analyzing IS research productivity: an inclusive approach to global IS scholarship. European Journal of Information Systems, 16(1), pp. 36-53.

Gorbacheva, E., Beekhuyzen, J., vom Brocke, J., \& Becker, J. (2019). Directions for research on gender imbalance in the IT profession. European Journal of Information Systems, 28(1), pp. 43-67.

Gupta, B., Loiacono, E. T., Dutchak, I. G., \& Thatcher, J. B. (2019). A field-based view on gender in the information systems discipline: preliminary evidence and an agenda for change. Journal of the Association for Information Systems, 2O(12), 2.

Guy, S. (2014). Second generation bias - A subtle but powerful presence. Consulting Specific Engineer, 2014.

Handley, I. M., Brown, E. R., Moss-Racusin, C. A., \& Smith, J. L. (2015). Quality of evidence revealing subtle gender biases in science is in the eye of the beholder. Proceedings of the National Academy of Sciences, 112(43), pp. 13201-13206.

Helmer, M., Schottdorf, M., Neef, A., \& Battaglia, D. (2017). Gender bias in scholarly peer review. Elife, 6, e21718.

Hengel, E., \& Moon, E. (2018). Gender and Quality at Top Economic Journals. Working paper: https://erinhengel. github. io/Gender-Quality/quality. pdf.

Hoffmann, C. P., Lutz, C., \& Meckel, M. (2014). Digital natives or digital immigrants? The impact of user characteristics on online trust. Journal of Management Information Systems, 31(3), pp. 138-171.

James, A., Chisnall, R., \& Plank, M. J. (2019). Gender and societies: a grassroots approach to women in science. Royal Society open science, 6(9), 190633.

Jaschik S (2014) Productivity or Sexism? Inside Higher Education. Available at https://www.insidehighered.com/news/2014/08/18/study-raises-questions-about-why-women-are-lesslikely-men-earn-tenure-research.

Joseph, D., Ang, S., \& Slaughter, S. A. (2015). Turnover or turnaway? Competing risks analysis of male and female IT professionals' job mobility and relative pay gap. Information Systems Research, 26(1), pp. 145164.

Kim, B., \& Han, I. (2009). What drives the adoption of mobile data services? An approach from a value perspective. Journal of Information Technology, 24(1), pp. 35-45. 
Kirton, G., \& Robertson, M. (2018). Sustaining and advancing IT careers: Women's experiences in a UKbased IT company. The Journal of Strategic Information Systems, 27(2), pp. 157-169.

Knobloch-Westerwick S, Glynn CJ, Huge M (2013) The Maltida effect in science communication: An experiment on gender bias in publication quality perceptions and collaboration interest. Sci Commun 35(5), pp. 603-625.

Krasnova, H., Veltri, N. F., Eling, N., \& Buxmann, P. (2017). Why men and women continue to use social networking sites: The role of gender differences. The Journal of Strategic Information Systems, 26(4), pp. 261-284.

Larivière V, Ni C, Gingras Y, Cronin B, Sugimoto CR (2013) Bibliometrics: Global gender disparities in science. Nature 504(7479), pp. 211-213.

Malik, F., \& Nicholson, B. (2020). Understanding the interplay of institutional logics and management practices in impact sourcing. Information Systems Journal, 3o(1), pp. 125-149.

Moss-Racusin CA, Dovidio JF, Brescoll VL, Graham MJ, Handelsman J (2012) Science faculty's subtle gender biases favor male students. Proc Natl Acad Sci USA 109(41), pp. 16474-16479.

Oreglia, E., \& Srinivasan, J. (2015). ICT, intermediaries, and the transformation of gendered power structures. MIS Quarterly, 4O(2), pp. 501-510.

Panteli, N. (2012). A community of practice view of intervention programmes: the case of women returning to IT. Information Systems Journal, 22(5), pp. 391-405.

Quesenberry, J. L., \& Trauth, E. M. (2012). The (dis) placement of women in the IT workforce: an investigation of individual career values and organisational interventions. Information Systems Journal, 22(6), pp. 457-473.

Reuben E, Sapienza P, Zingales L (2014) How stereotypes impair women's careers in science. Proc Natl Acad Sci USA 111(12), pp. 4403-4408.

Ridley, G., \& Young, J. (2012). Theoretical approaches to gender and IT: examining some Australian evidence. Information Systems Journal, 22(5), pp. 355-373.

Shen, A., Lee, M. K., Cheung, C. M., \& Chen, H. (2010). Gender differences in intentional social action: weintention to engage in social network-facilitated team collaboration. Journal of Information Technology, 25(2), pp. 152-169.

Shen, H (2013). Inequality quantified: Mind the gender gap. Nature 495.7439, pp. 22-24.

Trauth, E. M., \& Howcroft, D. (2006). Critical empirical research in IS: an example of gender and the IT workforce. Information Technology \& People, 19(3), pp. 272-292.

Trauth, E. M. (2002). Odd girl out: an individual differences perspective on women in the IT profession. Information Technology \& People.

Von Hellens, L., Trauth, E. M., \& Fisher, J. (2012). Increasing the representation of women in the information technology professions: Research on interventions. Information Systems Journal, 22(5), pp. 343-353.

Wilson, M. (2004). A conceptual framework for studying gender in information systems research. Journal of Information Technology, 19(1), pp. 81-92.

Winter, S. J., \& Saunders, C. (2019). The Personal in the Policy Cascade. Journal of the Association for Information Systems, $20(11), 1$.

Zahedi, F. M., Van Pelt, W. V., \& Srite, M. (2006). Web documents' cultural masculinity and femininity. Journal of Management Information Systems, 23(1), pp. 87-128. 